\title{
Choice, delay, probability, and conditioned reinforcement
}

\author{
JAMES E. MAZUR \\ Southern Connecticut State University, New Haven, Connecticut
}

\begin{abstract}
The hyperbolic-decay model is a mathematical expression of the relation between delay and reinforcer value. The model has been used to predict choices in discrete-trial experiments on delay-amount tradeoffs, on preference for variable over fixed delays, and on probabilistic reinforcement. Experiments manipulating the presence or absence of conditioned reinforcers on trials that end without primary reinforcement have provided evidence that the hyperbolic-decay model actually predicts the strength of conditioned reinforcers rather than the strength of delayed primary reinforcers. The model states that the strength of a conditioned reinforcer is inversely related to the time spent in its presence before a primary reinforcer is delivered. A possible way to integrate the model with Grace's (1994) contextual-choice model for concurrent-chain schedules is presented. Also discussed are unresolved difficulties in determining exactly when a stimulus will or will not serve as a conditioned reinforcer.
\end{abstract}

One of the most potent factors affecting an individual's choice behavior is delay of reinforcement. With animal subjects, numerous studies have shown that delays of just a few seconds can have dramatic affects on choice behavior (e.g., Ainslie, 1974; Green, Fisher, Perlow, \& Sherman, 1981; Rachlin \& Green, 1972). Human subjects can sometimes tolerate long delays, but there have been many examples in which brief delays have affected human choice behavior as well (e.g., Millar \& Navarick, 1984; Navarick, 1985, 1986; Solnick, Kannenberg, Eckerman, \& Waller, 1980).

Besides being powerful, the effects of reinforcer delay are also ubiquitous: It is difficult to think of many choice situations, either inside or outside the laboratory, that do not involve delays in one way or another. Consider, for example, two of the most common research procedures in operant research on choice - concurrent schedules and concurrent-chain schedules. By definition, concurrent schedules involve a choice between two or more simultaneously available reinforcement schedules. Except in the special case of continuous reinforcement schedules (CRF), in which every response is followed by a reinforcer, two concurrent schedules will each include delays (determined by the schedule, the subject's behavior, or both) between the first response on a schedule and the eventual delivery of a reinforcer. In concurrent-chain schedules, the delays are even more numerous, because these procedures

Preparation of this manuscript was supported by Grant MH 38357 from the National Institutes of Mental Health. I thank Michael Davison and Randy Grace for providing me with data sets from their research. Correspondence should be addressed to J. E. Mazur, Psychology Department, Southern Connecticut State University, New Haven. CT 06515 (e-mail: mazur@scsu.ctstateu.edu).

Note: This article is one of those occasionally invited by the editor in which authors have the opportunity to provide an overview of their research programs.--Editor include both "initial links" and "terminal links," each of which imposes its own delay to reinforcement.

Both concurrent schedules and concurrent-chain schedules have been the objects of intense research for several decades, and great progress has been made in understanding the factors that control behavior under these schedules. Nevertheless, perhaps because of the complexity of these schedules, there is still no consensus about what theoretical model best describes performance on them. In my own research, I have tried to avoid some of the complexity of these schedules by using discrete-trial choice procedures in which subjects choose between two alternatives by making a single, brief response. Because the choice period is so brief in this procedure, it usually constitutes a very small portion of the overall delay to reinforcement, and it seems fair to assume that its effects on the subject's choices will be minimal. In other words, we can assume that the subject's choices are controlled mainly by the events that occur after the choice period, not by delays inherent in the choice period itself.

This paper describes the theoretical model that has resulted from my research with discrete-trial choice procedures, which has been called the hyperbolic-decay model. The paper describes the model's application to a variety of choice situations, such as those involving delay-amount tradeoffs, preference for variable delays, probabilistic reinforcement, and conditioned reinforcers. It presents evidence that the hyperbolic-decay model offers a promising method for predicting the strength of a conditioned reinforcer. Finally, the paper discusses a number of unresolved issues that may be clarified by further research and theory development, including how the model might be applied to cases involving extended choice periods and under exactly what conditions a stimulus will and will not function as a conditioned reinforcer.

The discrete-trial procedure that I have used in much of my research is an adjusting-delay procedure. This proce- 
dure is described in detail because it was used in most of the experiments discussed in this manuscript, although various procedural details differed from one study to another.

\section{THE ADJUSTING-DELAY PROCEDURE}

In this procedure, a subject chooses between a standard alternative, for which the schedule of delays to reinforcement is constant throughout a condition, and an adjusting alternative, for which the delay is increased or decreased many times during a session depending on the subject's choices. The purpose of these adjustments is to estimate an indifference point, or a delay at which the two alternatives are chosen about equally often.

In one of my early experiments using the adjustingdelay procedure (Mazur, 1987), pigeons received experimental sessions that included a maximum of 60 trials, which were divided into blocks of 4 trials. Each block included two forced trials followed by two choice trials. Figure 1 illustrates the two possible sequences of events that could occur on a choice trial. At the start of a trial, the center key of a three-key chamber was transilluminated with white light. A single peck at the center key was required to begin the choice period. The purpose of this response on the center key was to increase the likelihood that the subject's head was equally distant from

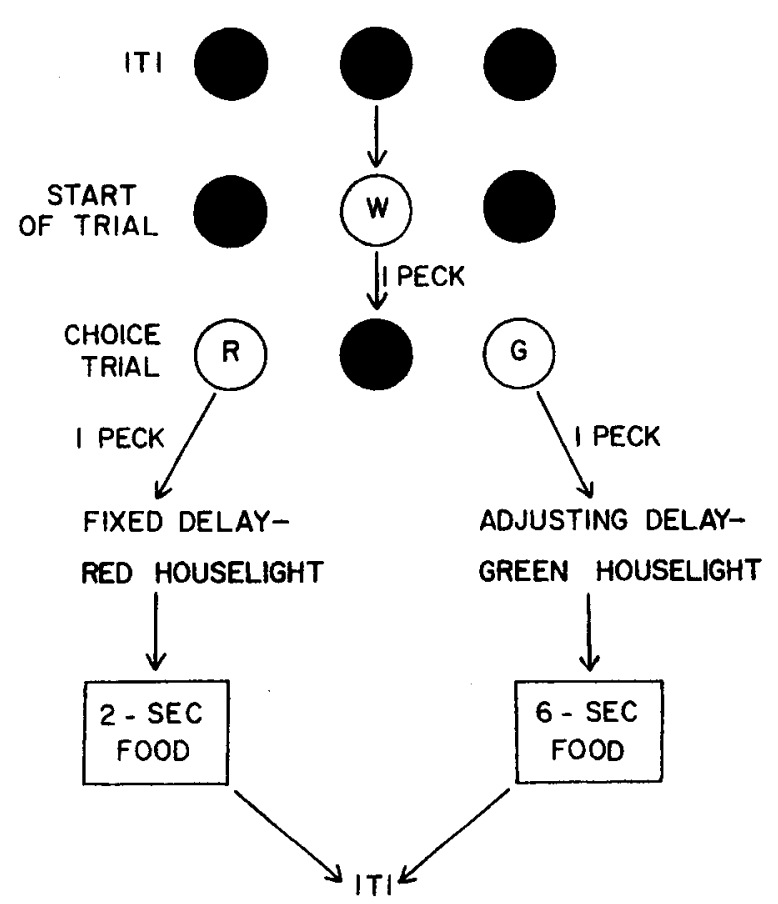

Figure 1. The two sequences of events that could occur on a choice trial in Mazur's (1987) experiment, depending on whether the red $(R)$ or green $(G)$ key was chosen. ITI, intertrial interval. From "An Adjusting Procedure for Studying Delayed Reinforcement," by J. E. Mazur, 1987. In M. L. Commons, J. E. Mazur, J. A. Nevin, and H. Rachlin (Eds.), Quantitative Analyses of Behavior, Vol. 5: The Effect of Delay and of Intervening Events on Reinforcement Value (pp. 55-73). Hillsdale, NJ: Erlbaum. Copyright 1987 by Erlbaum. Reprinted with permission. the two side keys when the choice period began. A center-key peck darkened this key and illuminated the two side keys, one red and one green. In this experiment, the red key was the standard key and the green key was the adjusting key. A peck at the red key extinguished both side keys and initiated the standard delay, during which the red houselights were lit instead of the white houselights. At the end of the standard delay, the red houselights were extinguished and grain was presented for $2 \mathrm{sec}$. After reinforcement, there was a 60 -sec intertrial interval (ITI) during which the houselights were white, and then the next trial began.

If the green key was pecked during the choice period, both side key colors were extinguished and the adjusting delay began, during which the green houselights were lit. The adjusting delay was followed by $6 \mathrm{sec}$ of access to grain and then a $60-\mathrm{sec}$ ITI. The procedure on forced trials was the same as that on choice trials except that only one side key was lit, red or green, and a peck at this key led to the appropriate delay. A peck at the opposite key, which was dark, had no effect. Every pair of forced trials included one with the red key and one with the green key, presented in random order.

After every two choice trials, the delay for the adjusting key could be changed. If a subject chose the adjusting key on both choice trials, the adjusting delay was increased by $1 \mathrm{sec}$. If the subject chose the standard key on both trials, the adjusting delay was decreased by $1 \mathrm{sec}$ unless it was already zero. If a subject chose each key on one trial, no change was made in the adjusting delay. In all three cases, this adjusting delay remained in effect for the next block of four trials.

The standard alternative remained the same for a minimum of 12 sessions, and until several stability criteria were met. Once the stability criteria were met, the mean adjusting delay in the last several sessions was treated as an estimate of the indifference point.

In this experiment, the standard delay was varied across conditions, and an equivalent adjusting delay (an indifference point) was estimated. Then the adjusting delays were plotted as a function of the standard delays, producing an indifference function for each subject. As explained in the next section, the results of this experiment were used to test several alternative mathematical models of delayed reinforcement.

\section{DIFFERENT MODELS OF THE DELAY-OF-REINFORCEMENT FUNCTION}

It has long been known that as the delay to a reinforcer increases, its reinforcing value (that is, its effectiveness in sustaining instrumental responding) decreases. However, different theories have proposed various equations to describe the relation between delay and reinforcer value. The study by Mazur (1987) was designed to test the predictions of four different delay-of-reinforcement equations. One equation states that reinforcer value decreases exponentially as its delay increases, as proposed by Hull (1943): 


$$
V=A e^{-K D},
$$

where $V$ represents value, $A$ is a measure of the amount of reinforcement, $e$ is the base of the natural logarithm, $D$ is the delay between a choice response and reinforcement, and $K$ is a free parameter that determines how sharply $V$ decreases with increases in $D$.

A second equation states that there is a simple reciprocal relation between $D$ and $V$ (see Ainslie, 1975; Baum \& Rachlin, 1969; McDiarmid \& Rilling, 1965; Shull \& Spear, 1987):

$$
V=\frac{A}{K D}
$$

One potential problem with Equation 2, however, is that it predicts that reinforcer value will grow infinitely large as delay approaches zero. This problem can be avoided by adding a constant to the denominator, which results in the following hyperbolic equation (see Gibbon, 1977):

$$
V=\frac{A}{1+K D} \text {. }
$$

A fourth equation also describes a hyperbolic function, but one in which $D$ is raised to some exponent, $B$, which might not equal 1 :

$$
V=\frac{A}{1+K D^{B}} .
$$

To derive predictions from these four equations for Mazur's (1987) experiment, we need only assume that at an indifference point the values of the standard and adjusting alternatives are equal (i.e., that $V_{\mathrm{L}}=V_{\mathrm{S}}$, where the subscripts refer to the large and small reinforcer amounts). Given this assumption, we can then solve for $D_{\mathrm{L}}$, the delay for the large reinforcer that makes it equal in value to the small reinforcer. It turns out that Equations 1-4 predict four different types of indifference curves for Mazur's (1987) experiment. Equation 1 (the exponential) predicts the following:

$$
D_{\mathrm{L}}=\ln \left(A_{\mathrm{L}} / A_{\mathrm{S}}\right) / K+D_{\mathrm{S}}
$$

As illustrated in Figure 2, Equation 1A predicts that the indifference curve will have a $y$-intercept greater than 0 and, more importantly, that its slope will equal 1 regardless of the amounts of reinforcement delivered by the two alternatives. It is the only one of the four equations to predict a slope of 1 .

Equation 2 (the simple reciprocal) predicts that the slope of the indifference curve will be greater than 1. More specifically, it predicts that the slope will be equal to the ratio $A_{\mathrm{L}} / A_{\mathrm{S}}$ :

$$
D_{\mathrm{L}}=\left(A_{\mathrm{L}} / A_{\mathrm{S}}\right) D_{\mathrm{S}}
$$

It should be emphasized that although the programmed reinforcer durations were 2 and 6 sec in Mazur's (1987) study, it is not assumed that the ratio $A_{\mathrm{L}} / A_{\mathrm{S}}$ is equal to 3 , but only that it is greater than 1 . The effect of tripling the duration of a reinforcer on the reinforcer's value is a mat-

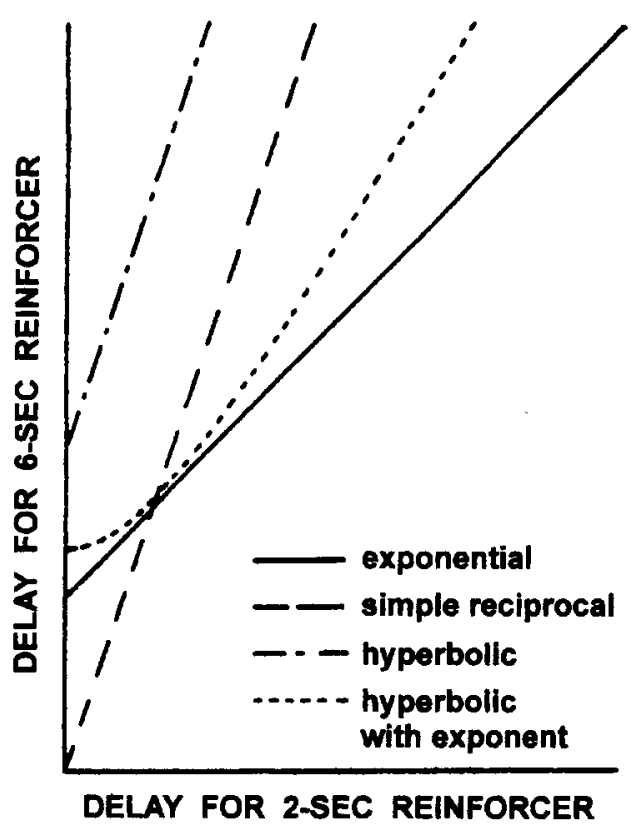

Figure 2. The predictions of four different delay equations are shown for Mazur's (1987) experiment, in which the standard delay led to a 2-sec reinforcer and the adjusting delay led to a 6-sec reinforcer. From "An Adjusting Procedure for Studying Delayed Reinforcement," by J. E. Mazur, 1987. In M. L. Commons, J. E. Mazur, J. A. Nevin, and H. Rachlin (Eds.), Quantitative Analyses of Behavior, Vol. 5: The Effect of Delay and of Intervening Events on Reinforcement Value (pp. 55-73). Hillsdale, NJ: Erlbaum. Copyright 1987 by Erlbaum. Reprinted with permission.

ter that would have to be settled empirically. In any case, the distinguishing feature of Equation 2 is that it predicts a $y$-intercept of 0 .

Like Equation 2, Equation 3 (the hyperbolic) predicts that the slope of the indifference curve will equal $A_{\mathrm{L}} / A_{\mathrm{S}}$, but unlike Equation 2, it predicts that the $y$-intercept will be positive:

$$
D_{\mathrm{L}}=\left(A_{\mathrm{L}}-A_{\mathrm{S}}\right) / K A_{\mathrm{L}}+\left(A_{\mathrm{L}} / A_{\mathrm{S}}\right) D_{\mathrm{S}}
$$

Finally, Equation 4 predicts a more complex relation between $D_{\mathrm{L}}$ and $D_{\mathrm{S}}$ :

$$
D_{\mathrm{L}}=\left[\left(A_{\mathrm{L}}-A_{\mathrm{S}}\right) / K A_{\mathrm{L}}+\left(A_{\mathrm{L}} / A_{\mathrm{S}}\right) D_{\mathrm{S}}^{B}\right]^{1 / B} .
$$

The hyperbolic with an exponent also predicts that the $y$ intercept will be positive, but if the exponent $B$ is not equal to 1 , it predicts a nonlinear indifference curve. This curvature is concave upward for values of $B$ greater than 1 and concave downward if $B$ is less than 1. Equation 4 is the only one of the four equations to predict a nonlinear indifference curve.

Figure 3 shows the indifference points generated by the four pigeons in Mazur's (1987) experiment. Regression lines are plotted for each bird's data, and the equations for these lines are shown in each panel. As can be seen, the results were well described by the regression lines, and for all subjects the slopes of these lines were 


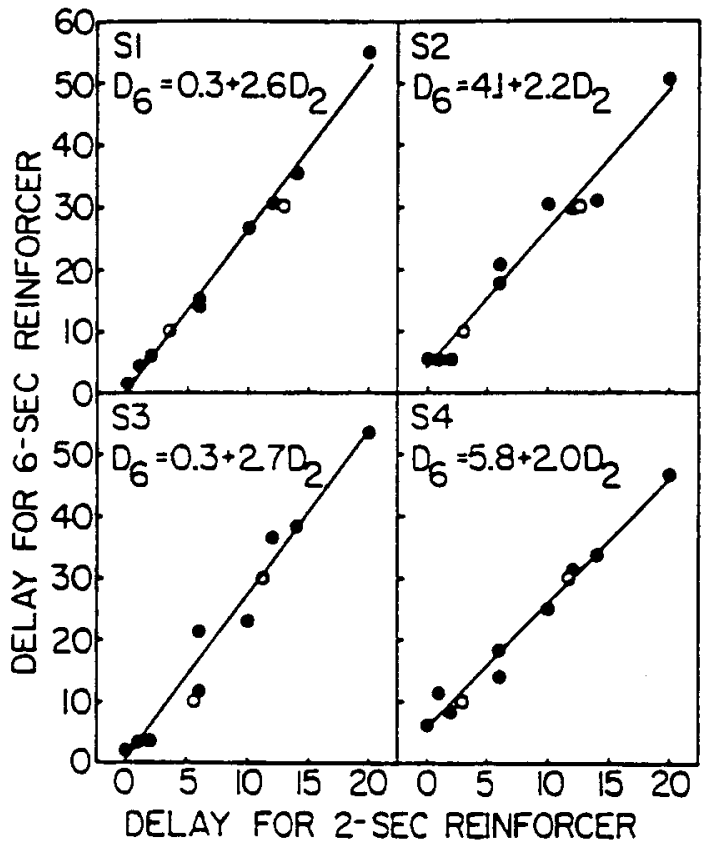

Figure 3. Indifference points (mean adjusting delays) are shown for each pigeon in Mazur's (1987) experiment. Regression lines are fitted to each subject's data. From "An Adjusting Procedure for Studying Delayed Reinforcement," by J. E. Mazur, 1987. In M. L. Commons, J. E. Mazur, J. A. Nevin, and H. Rachlin (Eds.), Quantitative Analyses of Behavior: Vol. 5. The Effect of Delay and of Intervening Events on Reinforcement Value (pp. 5573). Hillsdale, NJ: Erlbaum. Copyright 1987 by Erlbaum. Reprinted with permission.

greater than 2. These slopes therefore provide strong evidence against the suitability of Equation 1, which predicts slopes of 1 . Figure 3 also shows that the $y$-intercepts of the regression lines were greater than 0 for all subjects (significantly so for 2 of the subjects). The positive $y$-intercepts suggest that Equation 2 is not suitable, since it predicts $y$-intercepts of 0 . On the other hand, the results were fully consistent with Equation 3, which predicts positive $y$-intercepts and slopes greater than 1. Finally, because the results were well described by straight lines, there was no need to resort to the more complex Equation 4.

From this research, I concluded that the delay-ofreinforcement function can be well described by the hyperbolic equation, but not by the exponential or simple reciprocal equations. Other studies have replicated the results of this experiment and extended their generality. Rodriguez and Logue (1988) conducted a study with pigeons much like that of Mazur (1987) and obtained similar results, and they also obtained similar results with human subjects. Grossbard and Mazur (1986) replaced the delays of the preceding experiment with fixed-ratio (FR) schedules, which required a fixed number of responses between the choice response and reinforcement. They found similar indifference functions, as shown in Figure 4. This result suggests that Equation 3 can also be applied to ratio schedules, by letting $D$ represent the number of responses instead of delay. Another way to apply Equation 3 to these results, however, would be to measure the times required to complete the different ratios and treat these times as delays. When Grossbard and Mazur performed these calculations, the resultant indifference curves were very similar in form to those of Figure 4. Either way, the results were consistent with the hyperbolic-decay equation.

Although the hyperbolic-decay model has been supported by a number of experiments involving delayamount tradeoffs, several questions remain unanswered. One question concerns whether the decay parameter, $K$, remains constant as variables such as the amount of reinforcement are manipulated. The predictions of the various equations shown in Figure 2 are based on the assumption that $K$ remains constant, and the distinctions between the different models become blurred if $K$ varies as a function of reinforcer amount. For example, Green, Fristoe, and Myerson (1994) showed that if $K$ is inversely related to reinforcer amount, the exponential equation (Equation 1) also predicts indifference functions with slopes greater than 1, and its predictions therefore become more difficult to distinguish from those of Equation 3 . Green et al. cited the results of several studies with human subjects that revealed an inverse relation between $K$ and reinforcer amounts, so that reinforcer value declined more slowly for larger reinforcer amounts (see, e.g., Benzion, Rapaport, \& Yagil, 1989; Raineri \& Rachlin, 1993). After further analysis of their data, however, Myerson and Green (1995) concluded that they were consistent with a hyperbolic relation but not an exponential relation.

Another feature of the indifference functions Green et al. (1994) obtained from human subjects was that they had a slight but statistically significant downward curvature. This nonlinearity could mean that Equation 4, or some similar equation that includes an exponent, is necessary. It is difficult to compare these studies with human subjects and the animal studies because the procedures were markedly different. The experiments with pigeons used a primary reinforcer (food), delays of usually less than $1 \mathrm{~min}$, and conditions that each lasted for several sessions and hundreds of trials. Green et al. used hypothetical monetary reinforcers and hypothetical delays of up to 20 years, and each subject participated in a single session lasting less than $1 \mathrm{~h}$. In any case, the departures from linearity were small, and they occurred for some subjects but not others.

Another study I conducted with pigeons and the adjusting-delay procedure addressed this issue of whether more accurate predictions could be obtained if $D$ were raised to some exponent other than 1 (Mazur, 1986a). The pigeons chose between a single reinforcer delivered after an adjusting delay and a standard alternative that delivered (depending on the condition) either one, two, or three reinforcers in a sequence, each preceded by a fixed delay. It turns out that Equation 4 makes very different predictions for this experiment, depending on the size of the exponent, $B$. If $B$ were substantially different from 1 , it would have been easy to estimate its value from the slopes 


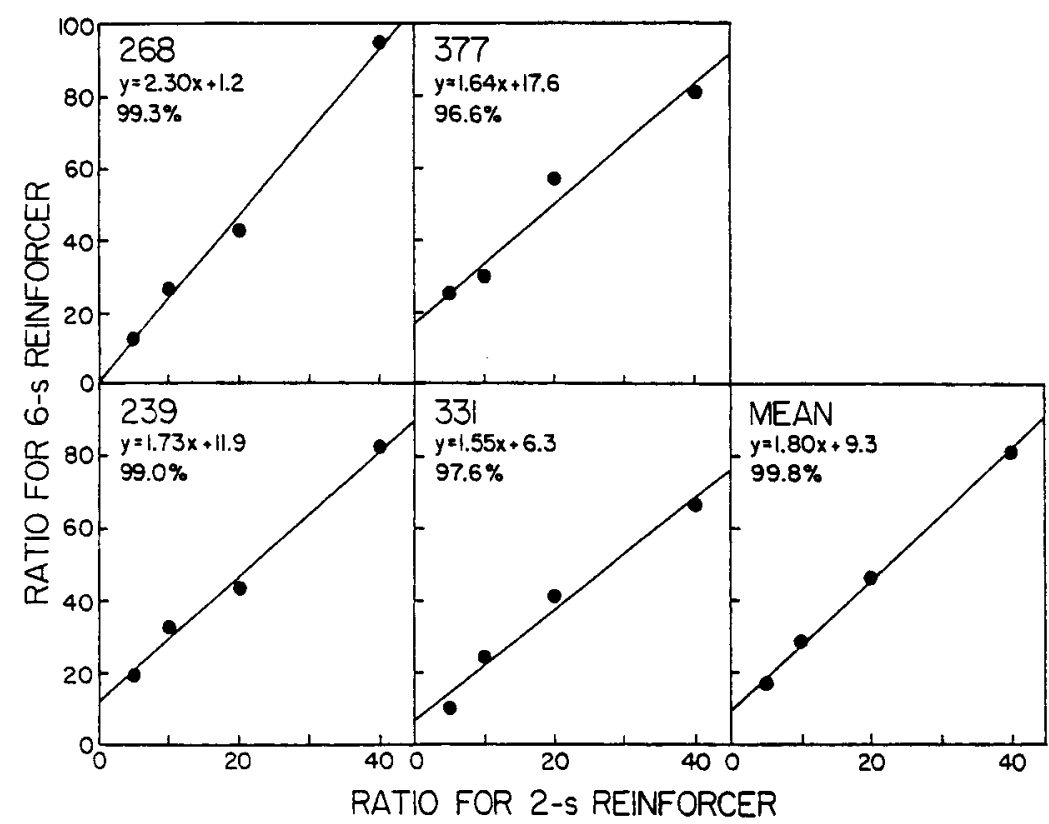

Figure 4. Indifference points (mean adjusting ratios) are shown for each pigeon in Grossbard and Mazur's (1986) experiment, in which pigeons chose between a standard ratio that led to a 2 -sec reinforcer and an adjusting ratio that led to a 6 -sec reinforcer. Regression lines are fitted to each subject's data.

of the indifference curves. However, the results of this study suggested that $B$ was equal or close to 1 . With $B=$ 1, Equation 4 reduces to Equation 3, and Equation 3 accounted for over $92 \%$ of the variance in mean indifference points in this study. These results, along with the linear indifference functions shown in Figures 3 and 4, suggest that the inclusion of an exponent other than 1 is not necessary, at least with pigeons.

Another unresolved question is whether Equation 3 actually describes the values of the primary reinforcers (food) or the values of the conditioned reinforcers that filled the delays between each choice response and the primary reinforcer (the red and green houselights). I originally assumed that Equation 3 described how the value of a primary reinforcer decreases with increasing delay, but based only on the data of Mazur (1987), one could just as easily conclude that the equation describes how the value of a conditioned reinforcer declines as its duration increases. Studies that help to distinguish between these two possible interpretations of Equation 3 are presented below.

\section{PREFERENCE FOR VARIABILITY}

Many studies have shown that animals will choose a reinforcement schedule with variable requirements over a schedule with fixed requirements that provides the same overall rate of reinforcement. For instance, both an FI 15-sec schedule and a variable-interval (VI) $15-\mathrm{sec}$ schedule deliver, on the average, one reinforcer every $15 \mathrm{sec}$, yet subjects exhibit a strong preference for the latter (see, e.g.. Herrnstein, 1964). This preference for variability has been found whether the two alternatives are interval schedules (Davison, 1969, 1972; Killeen, 1968), ratio schedules (Fantino, 1967; Navarick \& Fantino, 1972), or simple delays between a choice response and reinforcement (Cicerone, 1976; Rider, 1983). Most of these studies used extended-choice procedures, but similar results have been obtained with brief-choice procedures (Mazur, 1984, 1986b; Sherman \& Thomas, 1968).

Mazur (1984) showed that preference for variable over fixed delays can be predicted by the following extension of the hyperbolic-decay model:

$$
V=\sum_{i=1}^{n} P_{i}\left(\frac{A}{1+K D_{i}}\right)
$$

where $V$ is now the value of the variable alternative, which could deliver any one of $n$ possible delays on any given trial, and $P_{i}$ is the probability that a delay of $D_{i}$ seconds will occur. In short, this equation states that the value of a variable delay is an average of the values of all of its component delays, each weighted by its probability of occurrence.

To see how this equation predicts preference for variable delays, consider a choice situation in which a response on a green key leads to an FT 10-sec schedule (FT 10$\mathrm{sec})$ : A 10-sec delay with green houselights is followed by food. A response on a red key leads to a mixed-time 1-sec, 19-sec schedule (MT 1-sec, 19-sec): A delay of either 1 or $19 \mathrm{sec}$ with red houselights is followed by food. Although the amounts of food are equal, and the average delay to food is $10 \mathrm{sec}$ for both alternatives, animals exhibit a strong preference for the variable delay. 
Figure 5 provides a graphical illustration of how Equation 5 can be applied to this example. The parameters $A$ and $K$ have been arbitrarily set equal to 1 . Figure 5 shows that a reinforcer delayed just $1 \mathrm{sec}$ has a high value, an FT 10 -sec schedule has a much lower value, and an FT 19-sec schedule has the lowest value (but not much lower than the value of FT 10-sec). According to Equation 5, the value of the MT $1-\mathrm{sec}, 19-\mathrm{sec}$ schedule is the average of the values of FT 1-sec and FT 19-sec, and as shown in the figure, this average is substantially higher than the value of FT $10-\mathrm{sec}$. Therefore, the model predicts a preference for the MT 1-sec, 19-sec schedule over FT 10-sec

This model can also make more specific predictions about exactly what duration of an FT schedule would be equally preferred to MT $1-\mathrm{sec}, 19-\mathrm{sec}$. With $K=1$, Equation 5 derives a value of 0.275 for MT $1-\mathrm{sec}, 19-\mathrm{sec}$. If we use this value in the equation for a single fixed delay (Equation 3 ) and solve for $D$, we obtain a duration of $2.6 \mathrm{sec}$. The model therefore predicts that an FT 2.6-sec schedule will be equally preferred to MT 1-sec, 19-sec.

To test the predictions of this model, Mazur (1984) used the adjusting-delay procedure to present 4 pigeons with a series of MT schedules ranging from MT $0-\mathrm{sec}, 20-\mathrm{sec}$ to MT 7-sec, 13-sec, all of which had a mean delay to reinforcement of $10 \mathrm{sec}$. (In this study, and in most of the other studies described below, the durations of the ITIs were adjusted on a trial-by-trial basis so that the total time from a choice response to the start of the next trial was constant and equal for the standard and adjusting alternatives. The overall rate of reinforcement was therefore constant regardless of the subject's choices.) Figure 6 shows the indifference points for each MT schedule (and for two conditions that used an FT 10-sec schedule). The curves in each panel are the predictions of the hyperbolicdecay model.

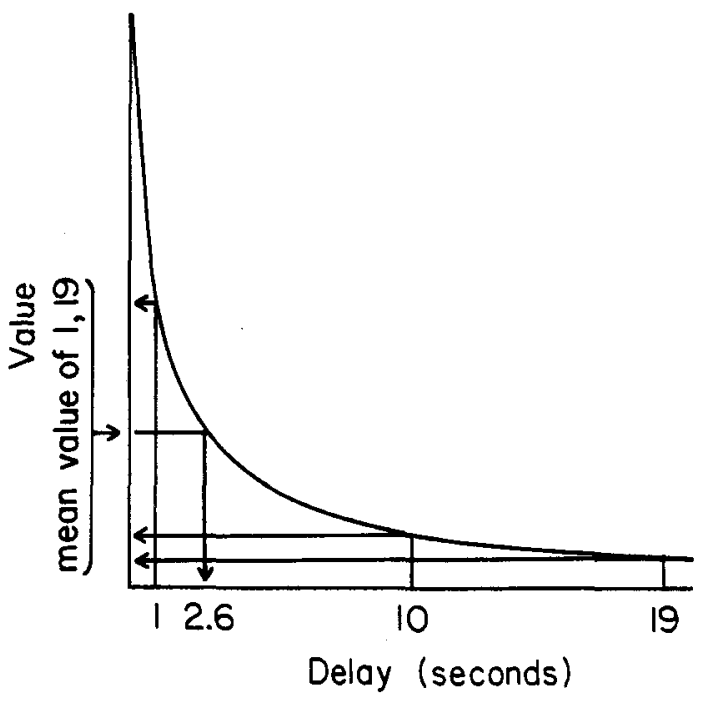

Figure 5. A hypothetical delay-of-reinforcement gradient based on the hyperbolic equation. Predicted values for fixed delays of 1, 10, and 19 sec are shown. According to Equation 5, the value of a mixed-time 1 -sec, 19-sec schedule is the average of the values of 1 - and 19-sec delays.
Several points can be made about these results. First, the equivalent adjusting delays for the FT 10 -sec schedules were higher than $10 \mathrm{sec}$ for most subjects, and this probably reflects either a color bias or a bias toward the adjusting alternative. (This bias for the adjusting alternative might itself be partly due to preference for variability, given that the adjusting delay varied slowly over trials.) The results from these and three other conditions with FT schedules were used to estimate the bias for each subject, and these estimates were taken into account in generating the predictions in Figure 6. Second, this figure shows, in dramatic fashion, how variability in the delays affected the subjects' choices. As the standard schedule changed from one with no variability (FT 10-sec) to one with extreme variability (MT 0 -sec, $20-\mathrm{sec}$ ), the indifference points ranged from about 11 to just over $1 \mathrm{sec}$. In the latter case, this suggests that an MT $0-\mathrm{sec}, 20-\mathrm{sec}$ schedule was about equally preferred to a fixed delay of about $1 \mathrm{sec}$.

Third, the predictions of the hyperbolic-decay model coincided quite well with the actual results, and they accounted for a large percentage of the variance in the data. However, to generate these predictions, $K$ was treated as a free parameter, and so this correspondence between predictions and results does not constitute the strongest possible test of the model. In other conditions of this experiment, parameter-free predictions were obtained from the model by using (1) an estimate of bias obtained from several different FT conditions and (2) estimates of $K$ obtained from the conditions shown in Figure 6 . The schedules used in these other conditions included MT, variable-time (VT), and random-time (RT) schedules. VT schedules are similar to MT schedules except that more than two different delays are used. In an RT schedule, there is a constant probability that the delay will end after each interval of time, so in the long run the delays approximate an exponential distribution. The results of several conditions involving MT schedules were first used to estimate the value of $K$ (which was 1.0 for the group as a whole), and then Equation 5 was used to make parameterfree predictions for 10 other conditions. The predictions proved to be quite accurate both for the indifference points of individual subjects and for the group averages. The left panel of Figure 7 compares the mean indifference points from each condition to the predictions of Equation 5, with $K=1$. This model accounted for over $95 \%$ of the variance in the data points.

For comparison, Mazur (1984) also tested the predictions of Killeen's (1982) incentive theory, which has been successfully applied to the results of several studies on preference for variability that used extended-choice procedures. For brief-choice procedures, Killeen's approach is similar to the analysis presented here, except that it uses another function to describe the relation between reinforcer delay and value:

$$
V=\left(e^{-q D}+1 / D\right) / D,
$$

where $q$ is a free parameter. Notice that, like Equation 2, Equation 6 states that value approaches infinity as delay 


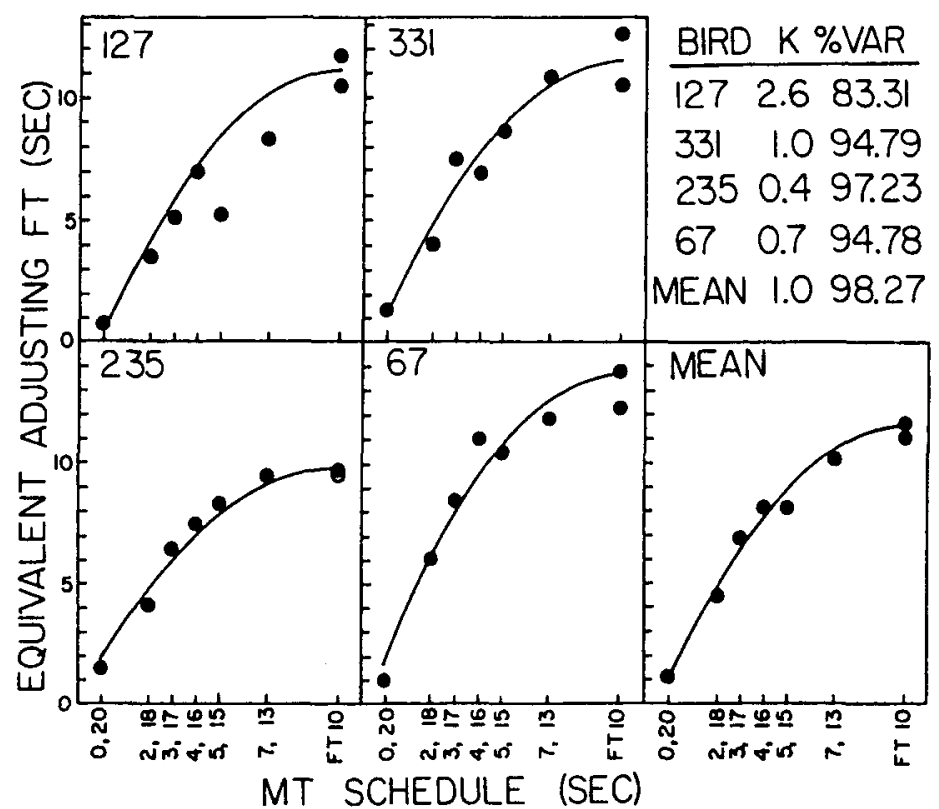

Figure 6. Indifference points from six mixed-time (MT) conditions and two fixed-time (FT) conditions are shown for each subject and the group mean in Mazur's (1984) experiment. The curves are the predictions of Equation 5 with $K$ treated as a free parameter. From "Tests of an Equivalence Rule for Fixed and Variable Reinforcer Delays," by J. E. Mazur, 1984, Journal of Experimental Psychology: Animal Behavior Processes, 10, p. 432. Copyright 1984 by the American Psychological Association. Reprinted with permission.

approaches 0 . As shown in the right panel of Figure 7 , its predictions account for only about $34 \%$ of the variance, and the advantage of the hyperbolic equation is apparent. Equation 5 has also been applied with some success to results from choices between fixed and variable ratio schedules, although the predictions may not be as accurate at a quantitative level as they are for fixed and variable delays (Field, Tonneau, Ahearn, \& Hineline, 1996; Mazur, 1986b).

This research on fixed and variable delays has served to demonstrate the generality of the hyperbolic-decay model, but it does not help us to decide whether the model actually describes the strengths of delayed primary reinforcers or of the conditioned reinforcers that occur during the delays. To distinguish between these two possibilities, we need to examine cases in which the frequencies and/or durations of the conditioned reinforcers and the primary reinforcers are independently manipulated, such as in probabilistic reinforcement, when a primary reinforcer is delivered on some trials but not others.

\section{CHOICE WITH PROBABILISTIC REINFORCERS}

Rachlin, Logue, Gibbon, and Frankel (1986) proposed that reinforcers that are delivered on a probabilistic basis are functionally equivalent to reinforcers delivered after a delay. For example, suppose that every time a pigeon chooses a red key, there is a 5-sec delay with red house- lights, and then food is delivered on $20 \%$ of the trials. On the other $80 \%$ of the trials, red houselights are also presented for $5 \mathrm{sec}$, but no food is delivered. In both cases, there is a $30-\mathrm{sec}$ ITI, and then the next trial begins. Under these circumstances, it will take an average of five redkey trials (separated by a total of four 30-sec ITIs) to obtain a reinforcer. Rachlin et al.'s theory therefore predicts that this probabilistic alternative should be equally preferred to a reinforcer that is delivered on $100 \%$ of the trials after a delay of $145 \mathrm{sec}$ (which is the sum of five 5sec delays plus four 30-sec ITIs).

Rachlin et al. (1986) found some support for their theory in an experiment in which college students made hypothetical monetary choices in a gambling situation. However, in a series of experiments with pigeons and the adjusting-delay procedure, I found two problems with this theory. The first problem concerned the effects of ITI duration on choice. In one experiment, red-key choices led to the consequences described in the preceding paragraph: There was a 5-sec delay with red houselights, and then food was presented with a probability of .2 . Each choice of a green key led to an adjusting delay with green houselights, and then food was presented with a probability of 1.0. In different conditions, the durations of the ITIs were varied so that the total time from a choice response to the start of the next trial was either 40 or $90 \mathrm{sec}$. According to Rachlin et al.'s theory, this should have had a dramatic effect on the adjusting delays, because the total time to food on the standard (red-key) alternative var- 


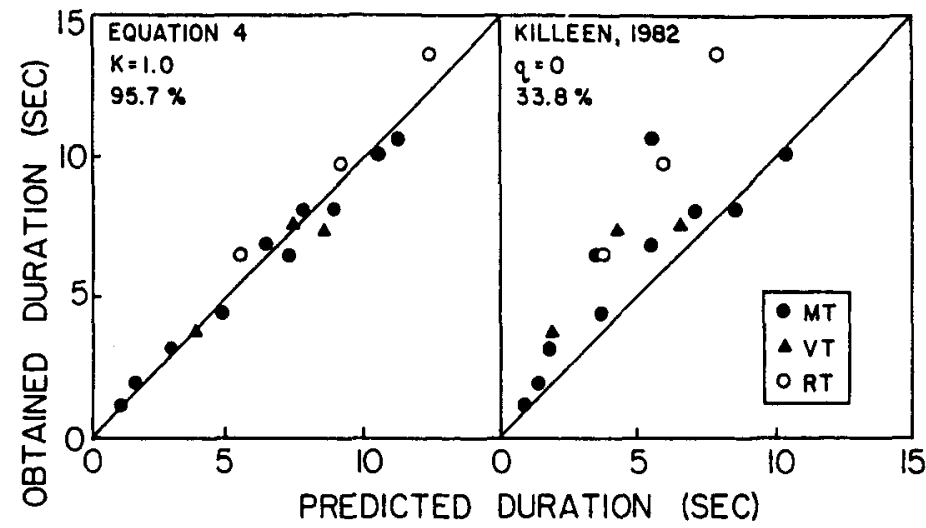

Figure 7. Mean indifference points from all the mixed-time (MT), variabletime (VT), and random-time (RT) conditions in Mazur's (1984) experiment are compared with the predictions of the hyperbolic-decay model (left panel) and with the predictions of Killeen's (1982) incentive theory (right panel). From “Tests of an Equivalence Rule for Fixed and Variable Reinforcer Delays," by J. E. Mazur, 1984, Journal of Experimental Psychology: Animal Behavior Processes, 10, p. 436. Copyright 1984 by the American Psychological Association. Reprinted with permission.

ied by several minutes with these two different ITIs. However, these variations in ITI duration had no systematic effect on adjusting delays. Similar results were obtained in another study with a reinforcer probability of .5 and the time between trials ranging from 30 to $90 \mathrm{sec}$.

These studies showed that ITI duration did not affect pigeons' indifference points in this choice situation. What did appear to affect the indifference points, however, was the amount of time spent in the presence of the red keylight and red houselights, because indifference points were longer when the reinforcement probability was .2 than when it was .5. (With lower reinforcement probabilities, there would of course be more presentations of the red keylight and houselights per food delivery.) The red and green keylights and houselights can be considered conditioned reinforcers, because they preceded and predicted the arrival of the primary reinforcer, food. These results therefore suggested the possibility that the pigeons' preferences were inversely related, not to the total time before a food delivery, but to the time spent in the presence of these conditioned reinforcers before a food delivery.

If the total duration of the conditioned reinforcers was the critical variable, the Rachlin et al. (1986) theory should make better predictions if ITI durations were simply excluded from the calculations. However, further analysis of the data revealed the second problem with the Rachlin et al. theory: Even when ITI durations were excluded, the model predicted indifference points that were systematically too long. For example, with a 5-sec delay and a .2 reinforcement probability, the model predicts indifference points of about 25 or $30 \mathrm{sec}$ (depending on whether the calculations include only the time spent in the presence of the red houselights or also include the brief time spent in the presence of the red keylights before a choice response is made). However, in several experi- ments, indifference points averaged about $17 \mathrm{sec}$ under these conditions.

To deal with these problems, Mazur (1989) suggested that the basic premise of the Rachlin et al. (1986) theory might be correct, but that probabilistic reinforcers were similar to reinforcers delivered after variable delays, not fixed delays. After all, with a reinforcement probability of .2, the average number of trials to food will be five, but on different occasions the actual number of trials to food will range from one to many more than five. If probabilistic reinforcers are indeed similar to reinforcers delivered after variable delays, it should be possible to apply Equation 5 in the same way that it was applied to variable delays. For instance, assuming a typical response latency of $1 \mathrm{sec}, D_{i}$ could be set to $6 \mathrm{sec}$ for those cases in which food was delivered after one red-key choice (to include the $1-\mathrm{sec}$ red keylight and 5-sec red houselights), to $12 \mathrm{sec}$ for those cases in which food was delivered after two redkey choices, and so on. Mazur (1989) applied these calculations to the results from several studies that included different combinations of reinforcer delays and probabilities and found that Equation 5 provided reasonably accurate predictions for choices between probabilistic and certain reinforcers.

Further evidence for the applicability of Equation 5 to cases involving probabilistic reinforcers was obtained in a subsequent experiment (Mazur, 1991, Experiment 2). This study also used an adjusting-delay procedure in which the total time from a choice response to the start of the next trial was always $30 \mathrm{sec}$. The delay for the standard alternative was $0 \mathrm{sec}$ in some conditions and $2 \mathrm{sec}$ in others, and the probability of reinforcement was varied from .1 to 1.0. For each condition, Figure 8 shows the mean indifference points - the equivalent adjusting delays for a reinforcer delivered with a probability of 1.0 . The solid 


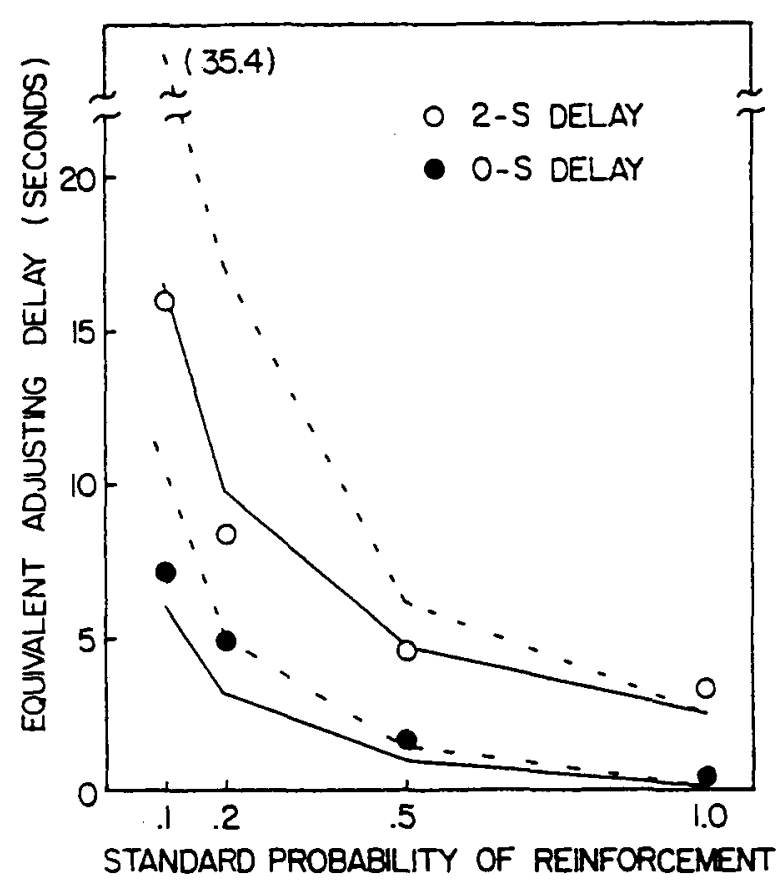

Figure 8. Mean indifference points from Experiment 2 of Mazur (1991) are compared with the predictions of the hyperbolic-decay model (solid lines) and the predictions of the Rachlin, Logue, Gibbon, and Frankel (1986) theory when intertrial-interval durations are excluded from the calculations (dashed lines).

lines show the predictions of Equation 5 with $K$ set at 0.3 (the value that produced the best fit using a least-squares criterion). The dashed lines show the predictions of the Rachlin et al. (1986) theory when ITI durations were excluded from the calculations. As can be seen, Equation 5 did a good job of describing the pattern of results, accounting for $95.5 \%$ of the variance in the group means. This figure also shows that, under certain circumstances, major reductions in the probability of reinforcement can have relatively little effect on choice behavior. For example, when the standard alternative featured a 0 -sec delay and a .l probability of reinforcement, the equivalent adjusting delay for a certain reinforcer was only about $7 \mathrm{sec}$ (even though the standard alternative would require an average of 10 trials, each separated by $30 \mathrm{sec}$, to produce one reinforcer). Although these indifference points may seem surprisingly small, they are accurately predicted by Equation 5, because $D_{i}$ includes only the durations of the colored keylights and houselights, not the ITIs.

\section{HYPERBOLIC DECAY AND THE ROLE OF CONDITIONED REINFORCERS}

Mazur's (1989) studies with probabilistic reinforcers in which ITI durations were varied provided one bit of evidence that $V$ in Equations 3 and 5 is best interpreted as the value of conditioned reinforcers, not the value of the delayed primary reinforcer. Whereas variations in the ITI duration substantially changed the total delay to the reinforcer for the probabilistic alternative, these variations had no perceptible effect on the indifference points. From a conditioned-reinforcement perspective, this insensitivity to ITI duration makes sense, however, because the amount of time spent in the presence of the conditioned reinforcers per food delivery did not change as ITI duration was varied. But much stronger evidence for the role of conditioned reinforcers has come from studies showing that subjects' preferences could be altered by varying the durations of the colored houselights, even though the total time to the primary reinforcer, food, was kept constant.

For example, in Mazur's (1989) third experiment, pigeons were exposed to pairs of conditions that included different arrangements of the red houselights that preceded food for the probabilistic alternative. The differences between these two conditions are shown in Figure 9. In red-present conditions (left panel), each choice of the standard alternative led to red houselights for $5 \mathrm{sec}$, and then food was presented with a probability of .2. In redabsent conditions (right panel), the only difference was that the red houselights were omitted on all trials that ended without food, so that on these trials a peck on the red key led directly to the white houselights of the ITI, which remained on until the next trial began. This change had a substantial effect on the pigeons' preferences: Indifference points averaged $17 \mathrm{sec}$ in the red-present conditions and $7 \mathrm{sec}$ in the red-absent conditions. In the adjusting-delay procedure, shorter indifference points reflect increased preference for the standard alternative, so this result indicates that preference for the standard alternative increased substantially when the red houselights were eliminated on no-food trials. This change in preference cannot be due to a change in the primary reinforcer because the probability of food and its delay were identical in the red-present and red-absent conditions. However, this change in preference can be readily explained by Equation 5 as long as $D_{i}$ is interpreted as the time spent in the presence of the conditioned reinforcers, because the time spent in the presence of the red houselights was decreased by $80 \%$ in the red-absent conditions.

Several other studies have confirmed this finding that reducing the duration of the conditioned reinforcers leads to an increase in preference for a probabilistic reinforcer (Mazur, 1991, 1995). Spetch, Dunn, and their colleagues have found similar results using somewhat different procedures (e.g, Dunn \& Spetch, 1990; Spetch, Belke, Barnet, Dunn, \& Pierce, 1990; Spetch, Mondloch, Belke, \& Dunn, 1994). In one comparison, for example, a single peck on either of two response keys led to a 5-sec delay, and then food might be presented (Spetch et al., 1990). One key delivered food on $100 \%$ of the trials, and a single key color was present during each 5-sec delay for this alternative. The other key delivered food after a $5-\mathrm{sec}$ delay, but only on $50 \%$ of the trials. In signaled conditions, one key color was present during the 5-sec delay on food trials, and a different color was present on nofood trials. In unsignaled conditions, either of the two key colors might be presented on any trial, whether or not the 

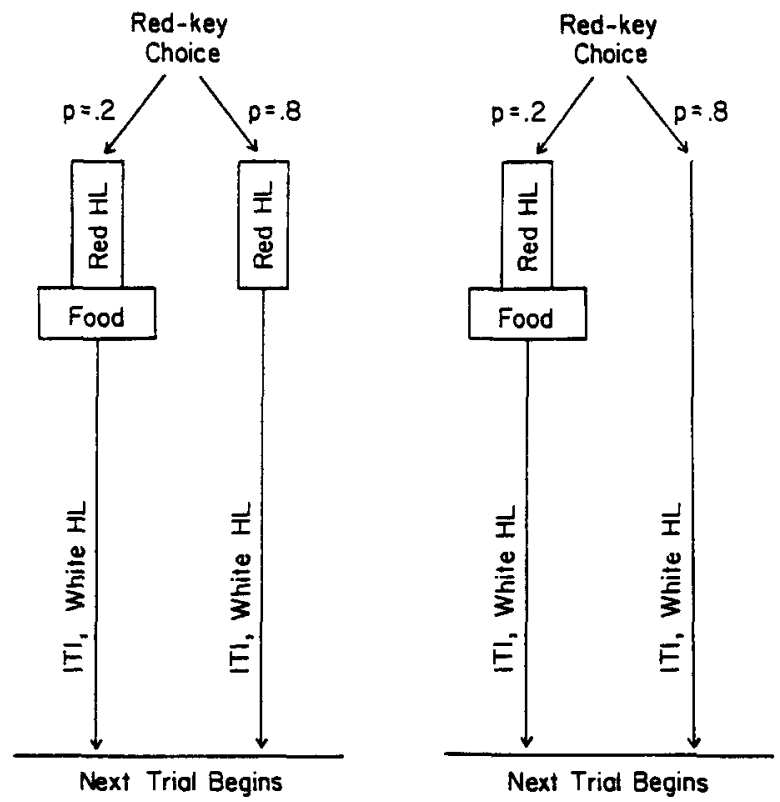

Figure 9. The two sequences of events that could occur after a red-key peck in the red-present conditions (left) and in the redabsent conditions (right) in Experiment 3 of Mazur (1989). HL, houselight; ITI, intertrial interval.

trial ended with food. The pigeons chose the $50 \%$ alternative much more frequently in signaled conditions than in unsignaled conditions. This result is in general agreement with the approach to conditioned reinforcement described above. The signaled conditions are analogous to the red-absent conditions of Mazur (1989), because a single stimulus was always present during the delays on food trials, but never on no-food trials. The unsignaled conditions are analogous to the red-present conditions, except that there were actually two conditioned reinforcers for the $50 \%$ alternative, either of which might or might not be followed by food. Because the time spent in the presence of these conditioned reinforcers per food delivery was greater in the unsignaled conditions, Equation 5 predicts the decreased preference for the $50 \%$ alternative that was observed. In other studies, these researchers found similar differences between signaled and unsignaled conditions with a number of different procedural variations.

Some of the most convincing evidence for the critical role of conditioned reinforcers comes from conditions in which subjects showed a preference for $50 \%$ reinforcement over $100 \%$ reinforcement, even though the delays for the two alternatives were identical. Mazur (1995) used an adjusting-delay procedure in which the red key was the adjusting key and the green key was the standard key. In all conditions, the time from a choice response to the start of the next trial was kept constant at 50 sec. Table 1 shows the consequences of choosing the green key in four different conditions of this experiment. In Condition $\mathrm{G} 10+, \mathrm{G} 30+$, a green-key peck led to a delay of either 10 or $30 \mathrm{sec}$ (with green houselights present), and then food was delivered on $100 \%$ of the trials. Therefore, in this condition, the mean delay to food (and the mean duration of the green houselights) was $20 \mathrm{sec}$. However, the mean adjusting delay in this condition was $14.2 \mathrm{sec}$, which provides a further example of preference for variability. In Condition G10+, G30-, the procedure was identical except that food was omitted on all trials with the $30-\mathrm{sec}$ green houselights (so only $50 \%$ of the greenkey trials ended with food). As might be expected (and as predicted by Equation 5), preference for the green key decreased in this condition-the mean adjusting delays increased to $17.7 \mathrm{sec}$.

Condition $\mathrm{Gl0} 10^{+}$, W50 - was similar to Condition G10+, G30- except that the 30-sec green houselights on no-food trials were eliminated. That is, on half the trials there were green houselights for $10 \mathrm{sec}$, then food, and on the other half, there were only white houselights for $50 \mathrm{sec}$, and then the next trial began. Although food was presented only on $50 \%$ of the green-key trials, Equation 5 predicts that the green key will actually be more strongly preferred than in Condition $\mathrm{Gl} 10+, \mathrm{G} 30+$, where food was delivered on $100 \%$ of the trials. This is because the duration of the green houselights per food delivery was $10 \mathrm{sec}$ in Condition $\mathrm{G} 10+$, W50-, compared to $20 \mathrm{sec}$ in Condition $\mathrm{G10}+\mathrm{G} 30+$. This prediction was confirmed: The mean adjusting delay in the $\mathrm{Gl0}+$, W50- condition was $9.4 \mathrm{sec}$, significantly shorter than in the $\mathrm{Gl0}+\mathrm{G} 30+$ condition. In other words, the pigeons showed an increased preference for the standard alternative when food was eliminated on half of the trials (provided that the 30 -sec green houselights were eliminated on those trials as well).

This comparison, plus many of the results described previously, shows that the presence or absence of a distinctive stimulus during a delay can have large effects on a subject's preference. But will any distinctive stimulus that marks a delay interval have such an effect, or must the stimulus be a conditioned reinforcer-a stimulus that it is at least occasionally followed by food? The result from Condition G10+, O30 - in Mazur's (1995) experiment provided some evidence on this question (Table 1 ). This condition was similar to Condition $\mathrm{Gl0}$, G30- except that the 30-sec green houselights on no-food trials were replaced with $30-\mathrm{sec}$ orange houselights. Notice that these orange houselights were not presented at any other time, and they were never paired with food, so they

\section{Table 1}

Possible Outcomes After a Choice of the Green (Standard) Key in Four Conditions of Mazur's (1995) Experiment

\begin{tabular}{cc} 
Condition & \multicolumn{1}{c}{ Possible Outcomes } \\
G10+, G30+ & $\begin{array}{l}\text { 10-sec green houselights, then food } \\
\text { or: } 30-\mathrm{sec} \text { green houselights, then food } \\
10-\mathrm{sec} \text { green houselights, then food } \\
\text { or: } 30-\mathrm{sec} \text { green houselights, no food }\end{array}$ \\
$\mathrm{G} 10+, \mathrm{G} 30-\mathrm{W} 50-$ & $\begin{array}{l}10-\mathrm{sec} \text { green houselights, then food } \\
\text { or: } 50-\mathrm{sec} \text { white houselights, no food } \\
10-\mathrm{sec} \text { green houselights, then food } \\
\text { or: } 30-\mathrm{sec} \text { orange houselights, no food }\end{array}$ \\
\hline
\end{tabular}


cannot be considered conditioned reinforcers. Because they were not conditioned reinforcers, they should not be included in the calculation of $D_{i}$ in Equation 5, and therefore the equation predicts that the results of this condition should be the same as those in Condition G10+, W50-. The results were, in fact, quite similar, with a mean adjusting delay of $9.1 \mathrm{sec}$, and this was again significantly different from the results of Condition $\mathrm{G} 10+, \mathrm{G} 30+$. This condition therefore provides a second case in which $50 \%$ reinforcement was preferred over $100 \%$ reinforcement. The results of this experiment provided not only qualitative but also quantitative support for predictions of the hyperbolic-decay model: With $K$ set equal to 1, Equation 5 accounted for $91.8 \%$ of the variance in group means across all the conditions of the experiment.

A similar comparison in another experiment also revealed that the presence of a distinctive stimulus in a delay interval had no effect on preference if that stimulus was never paired with food (Mazur, 1991, Experiment 1). Taken together, the results of these studies suggest that the hyperbolic-decay model is best interpreted as a model that predicts the strength of conditioned reinforcers, not the strength of delayed primary reinforcers.

As a model of conditioned reinforcement, Equation 5 may appear to be deficient in at least one respect: It includes no variable to take into account the rate at which conditioned reinforcers are delivered. Studies have shown that if the rate of primary reinforcement is equal for two alternatives, but one alternative delivers conditioned reinforcers at a higher rate, subjects will exhibit a preference for this alternative (Dunn, Williams, \& Royalty, 1987; Williams \& Dunn, 1991). However, rate of conditioned reinforcement is a difficult concept to define in a discretetrial procedure, and the studies demonstrating the effects of the rate of conditioned reinforcement have been conducted using concurrent-chain procedures. This issue is therefore addressed in the next section, after a possible method for applying the hyperbolic-decay model to cases involving extended-choice periods is introduced.

\section{COMPARISON WITH OTHER MODELS OF DELAYED REINFORCEMENT}

A different model of delayed reinforcement and conditioned reinforcement- - one that has had considerable success in predicting choice in concurrent-chain procedures - is delay-reduction theory (see, e.g., Fantino, 1969; Fantino \& Dunn, 1983; Fantino, Preston, \& Dunn, 1993; Squires \& Fantino, 1971). Delay-reduction theory and the hyperbolic-decay model differ in several ways, but two in particular are worth noting. First, unlike the hyperbolic-decay model, delay-reduction theory offers no clear explanation for why animals exhibit preference for variable over fixed reinforcement schedules, or for variable over fixed delays. To make predictions about choice between two reinforcement schedules, delay-reduction theory uses simple arithmetic means of the delays to reinforcement, whereas the many studies cited above clearly show that predictions based on arithmetic means are inappropriate when the alternatives are one fixed and one variable schedule. There may be ways to modify delayreduction theory to account for preference for variability, especially since the theory has some close similarities to Killeen's (1982) incentive theory, which does predict this phenomenon (see Killeen \& Fantino, 1990). So far, however, Fantino and his associates have not attempted to extend the theory in this way (see Fantino et al., 1993).

Perhaps the most fundamental difference between the two models, however, concerns the feature that gives delay-reduction theory its name-its assumption that the strength of a conditioned reinforcer is determined not by the absolute delay to reinforcement that it signals, but by the reduction in delay to reinforcement that it signals. This feature can be illustrated by examining a simple example of a concurrent-chain schedule, the sort of schedule for which delay-reduction theory frequently makes accurate predictions. Consider a concurrent-chain schedule in which the initial links are two independent VI 60sec schedules. During the initial links, the response keys for the two schedules are both white. The terminal link for the left consists of a $20-\mathrm{sec}$ delay followed by food, and the terminal link for the right key consists of a 40 sec delay followed by food. That is, whenever the subject completes the left VI schedule, the left key turns red, the right key is darkened, and food is presented after $20 \mathrm{sec}$. Whenever the subject completes the right VI schedule, the right key turns green, the left key is darkened, and food is presented after $20 \mathrm{sec}$. Immediately after reinforcement, both keys turn white again, and the initial-link VI schedules are again in effect.

To make predictions for this choice situation, we can use the delay-reduction theory in its simplest form:

$$
\frac{B_{\mathrm{L}}}{B_{\mathrm{L}}+B_{\mathrm{R}}}=\frac{\left(T-t_{2 \mathrm{~L}}\right)}{\left(T-t_{2 \mathrm{~L}}\right)+\left(T-t_{2 \mathrm{R}}\right)} .
$$

$B_{\mathrm{L}}$ and $B_{\mathrm{R}}$ are the response rates on the left and right initial links, $t_{2 \mathrm{~L}}$ and $t_{2 \mathrm{R}}$ are the durations of the left and right terminal links, and $T$ is average time to reinforcement from the onset of the initial link, including both initial-link and terminal-link durations. In this example, $t_{2 \mathrm{~L}}$. is $20 \mathrm{sec}, t_{2 \mathrm{R}}$ is $40 \mathrm{sec}$, and $T$ is $60 \mathrm{sec}$ (because with two VI $60-\mathrm{sec}$ schedules running concurrently, the average initial-link time will be $30 \mathrm{sec}$, and the average terminal link time is also $30 \mathrm{sec}$, the mean of the two terminal-link delays $)$. Solving Equation 7 , we find that $B_{\mathrm{L}} /\left(B_{\mathrm{L}}+B_{\mathrm{R}}\right)=$ .67 , so delay-reduction theory predicts that subjects will make $67 \%$ of their initial-link responses on the left key.

One of the many strengths of the delay-reduction theory is that it correctly predicts the initial-link effect-the finding that subjects' preferences for the shorter of two terminal links decreases as the durations of the two (equal) initial links increase. For example, consider a second condition in which the terminal links are unchanged, but the initial links are now two VI 180 -sec schedules. The average time in the initial links will now be $90 \mathrm{sec}$, and so $T$ is now $120 \mathrm{sec}$. According to Equation $7, B_{\mathrm{L}} /\left(B_{\mathrm{L}}+B_{\mathrm{R}}\right)=$ 
.56 , so delay-reduction theory predicts that subjects will show much weaker preference for the left key in this second condition. Studies have shown that this is indeed the result when initial-link durations are increased (Fantino, 1969, 1977). Similarly, delay-reduction theory correctly predicts the terminal-link effect, in which preference for the shorter terminal link increases as both terminal links are lengthened by identical proportions (MacEwen, 1972; Williams \& Fantino, 1978).

In summary, delay-reduction theory states that the strength of a conditioned reinforcer (such as the stimulus associated with the onset of a terminal link) is not a fixed characteristic of the delay to primary reinforcement. Rather, the strength of a conditioned reinforcer depends on the overall context in which it appears. A stimulus that signals a delay of a specified duration will be a strong conditioned reinforcer if it represents a large reduction in the delay to the primary reinforcer, but it will be weak if it represents only a small delay reduction.

In contrast, the hyperbolic-decay model makes no clear predictions about the initial-link effect, the terminal-link effect, or, in general, how the duration of the initial links will affect preference. As explained earlier, the model was developed to predict choice in procedures with very brief choice periods. Although there has been at least one attempt to apply the hyperbolic-decay model to concurrentchain procedures (Davison, 1988), this extension was suitable for only a limited range of situations.

How could the hyperbolic-decay model be generalized to choice situations involving initial links of extended durations? The main issue is this: Numerous studies on concurrent-chain schedules have shown that choice behavior is affected by the durations of both the initial links and the terminal links, but exactly how to incorporate these two factors into a single model has not yet been settled. One promising alternative, however, is Grace's (1993, 1994) contextual-choice model, which has been presented as a model of concurrent-chain performance that does not include the principle of delay reduction but can nevertheless account for findings from many experiments involving concurrent-chain procedures. A detailed description of this model is beyond the scope of this paper, but the main features of this model can be explained by presenting its basic equation:

$$
\frac{B_{\mathrm{L}}}{B_{\mathrm{R}}}=b\left(\frac{r_{\mathrm{LL}}}{r_{\mathrm{R}}}\right)^{a 1}\left(\frac{r_{2 \mathrm{~L}}}{r_{2 \mathrm{R}}}\right)^{a 2\left(T_{t} / T_{i}\right)^{k}} .
$$

$B_{\mathrm{L}}$ and $B_{\mathrm{R}}$ are response rates for the left and right alternatives, respectively, $b$ is a parameter than reflects any bias for the left or right alternative, $r_{\mathrm{IL}}$ and $r_{\mathrm{IR}}$ are the mean initial-link reinforcement rates for the two alternatives, and $r_{2 \mathrm{~L}}$ and $r_{2 \mathrm{R}}$ are the mean terminal-link reinforcement rates for the two alternatives. 'The exponents $a 1$ and $a 2$ reflect a subject's sensitivities to the initial-link and terminal-link schedules, respectively. $T_{t}$ is the average terminal-link duration, $T_{i}$ is the average initial-link duration, and $k$ is a scaling constant. According to this model, choice in a concurrent-chain procedure is affected by
(1) the schedules in the initial links $\left(r_{1 \mathrm{~L}}\right.$ and $\left.r_{1 \mathrm{R}}\right)$ and the subject's sensitivity $(a 1)$ to differences in these schedules, (2) the schedules or delays in the terminal links $\left(r_{2 L}\right.$ and $r_{2 \mathrm{R}}$ ) and the subject's sensitivity $(a 2)$ to differences in these schedules, and (3) the relative durations of the initial and terminal links, as represented by the exponent $T_{t} / T_{i}$. This exponent is included to give more weight to whichever link lasts for a longer period of time. This feature allows the model to account for phenomena such as the initial-link effect and the terminal-link effect without relying on the concept of delay reduction. For instance, for the example of the terminal-link effect described above, Equation 8 also predicts that preference for the left key will decrease and approach indifference as the initial links are lengthened. The model makes this prediction because as the initial links are lengthened, $T_{t} / T_{i}$ gets smaller, so the ratio of the reinforcement rates of the terminal links $\left(r_{2 \mathrm{~L}} / r_{2 \mathrm{R}}\right)$ has less effect on choice.

The contextual-choice model has a number of desirable features. First, for concurrent VI VI schedules (in which there are no terminal links, but the two VI schedules lead directly to food), the model reduces to the generalized matching law, which has been widely applied to concurrent schedule choice (Baum, 1974, 1979). Second, compared with other well-known models of concurrent-chain performance, the contextual-choice model's predictions fare very well. Grace (1994) tested the predictions of his model and those of three other models (Davison \& Temple, 1973; Killeen, 1982; Squires \& Fantino, 1971) using 10 archival data sets from experiments on concurrentchain schedules. The contextual-choice model accounted for an average of $91 \%$ of the variance in these studies, whereas the other three models each accounted for less than $60 \%$ of the variance.

It is not difficult to imagine how the principle of hyperbolic decay could be incorporated into the contextualchoice model. First, assuming that $V$ in the hyperbolicdecay model provides accurate estimates of the values of the conditioned reinforcers that are presented in the terminal links, estimates of $V_{2 L}$ and $V_{2 R}$ calculated from Equation 5 could replace $r_{2 L}$ and $r_{2 R}$. In fact, Grace (1996) has made a similar suggestion, and one advantage of making this change is the hyperbolic-decay model's success in predicting choice between fixed and variable schedules. Without this change, the contextualchoice model does not predict preference for variability and cannot be applied to situations in which one terminal link is a fixed schedule and the other is a variable schedule.

Taking this approach one step further, the initial-link reinforcement rates in Equation 8 could be replaced with $V_{1 \mathrm{~L}}$ and $V_{1 \mathrm{R}}$, two measures of initial-link values also derived from Equation 5. These values would be calculated as follows: For each key, the values of $D_{i}$ would represent the interreinforcement intervals for the two VI schedules in the initial links. To take a concrete example, in some conditions of Davison's (1983) experiment, the two initial links were independent VI 60-sec schedules that had interreinforcement intervals that ranged from 5 to $115 \mathrm{sec}$ 
in 10 -sec increments. These 12 interreinforcement intervals would be used as values of $D_{i}$ in Equation 5 to estimate $V_{1 \mathrm{~L}}$ and $V_{1 \mathrm{R}}$, the "values" of the two initial-link reinforcement schedules. Notice, however, that these values for the initial links have a different meaning from those of the terminal links, because the initial links never lead directly to food, but only to the terminal links. These two initial-link values, $V_{1 \mathrm{~L}}$ and $V_{2 \mathrm{~L}}$, might be called hyperbolic means of the initial-link reinforcement rates, and they reflect only the rates of entering the two terminal links and have nothing to do with the values of the two terminal links themselves.

Applying these changes, this integration of the hyperbolic-decay equation and the contextual-choice model becomes

$$
\frac{B_{\mathrm{L}}}{B_{\mathrm{R}}}=b\left(\frac{V_{1 \mathrm{~L}}}{V_{\mathrm{IR}}}\right)^{a 1}\left(\frac{V_{2 \mathrm{~L}}}{V_{2 \mathrm{R}}}\right)^{a 2\left(T_{t} / T_{i}\right)^{k}} .
$$

To test the viability of this approach, I conducted computer simulations to compare the accuracy of the original contextual-choice model (Equation 8) and Equation 9, using the two most extensive data sets that Grace (1994) included in his analyses (Davison, 1983; Fantino \& Davison, 1983). Each of these experiments included 6 pigeons exposed to 50 or more different conditions. Grace found that the contextual-choice model accounted for an average of $82 \%$ and $92 \%$ of the variance in these two studies, respectively. My computer simulations verified Grace's results exactly for each of the 12 individual subjects, thus indicating that my simulation program was applying the contextual-choice model in the same way that Grace did. Next, I modified the simulations to use Equations 5 and 9 (with $K$ in Equation 5 set equal to 1, so the number of free parameters was the same). Although the parameter estimates for $a 1$ and $a 2$ were somewhat different when Equation 9 was used, this approach accounted for very similar percentages of the variance for individual subjects (with a slight advantage for Equation 9 in some cases and for Equation 8 in others). Averaged across subjects, Equation 9 also accounted for $82 \%$ and $92 \%$ of the variance in the two studies. Overall, then, the predictions of Equations 8 and 9 were very similar for these data sets.

This approach can also explain the results of studies that found a preference for whichever alternative delivered a higher rate of conditioned reinforcers, when the rate of primary reinforcement was equal for the two alternatives (Dunn et al., 1987; Williams \& Dunn, 1991). For instance, Williams and Dunn used a concurrent-chain procedure with VI schedules as the initial links and FI 20sec schedules as the terminal links. The number of food presentations was the same for both the left and right alternatives, and the same stimulus (e.g., a green keylight on the center key) was present during the terminal links for both alternatives. However, not all terminal links ended with food, and the number of terminal links without food was greater for one alternative than for the other. Williams and Dunn observed a preference for whichever al- ternative delivered the greater number of conditioned reinforcers (terminal-link entries). They used these results to argue that the rate of conditioned reinforcement can affect preference even when the rate of primary reinforcement is equated.

It is not difficult to account for these results using Equation 9. Because the same stimulus (the green keylight) served as the conditioned reinforcer for both alternatives, we will assume that both terminal links had equal value. Therefore, the ratio $V_{2 \mathrm{~L}} / V_{2 \mathrm{R}}$ equals 1 , and choice is determined solely by $V_{1 \mathrm{~L}} / V_{1 \mathrm{R}}$, the ratio of the two initial-link values, which depends on the rates of terminal-link entries for the two alternatives. This equation therefore predicts a preference for whichever alternative leads to more terminal-link entries, even though not every terminal-link entry ends with food. This analysis ignores some possible complications (such as the possibility that a single stimulus, the blue keylight, might have different conditioned reinforcing values for the two different terminal links). Such complicating factors are discussed in the next section. Nevertheless, this example shows that Equation 9 may provide a simple way to account for the effects of different rates of conditioned reinforcement.

Although this blending of the hyperbolic-decay model and the contextual-choice model worked well for these studies, it would certainly be premature to conclude that this is the best way to extend the hyperbolic-decay model to extended-choice procedures. It is easy to imagine many other possible ways to apply the hyperbolic equation to concurrent-chain schedules (including both minor variations of Equation 9 and completely different approaches). But the hyperbolic-decay model has been quite successful in predicting preferences in discrete-trial choice procedures, and in my opinion, it seems unlikely that one set of principles applies to discrete-trial choice and a completely different set to situations with extended choice periods. If the same general principles do in fact apply to both situations, there should be a way to extend a model of discrete-trial choice to the more complex concurrentchain procedure.

\section{WHEN IS A STIMULUS A CONDITIONED REINFORCER?}

Putting aside the question of how it might be applied to situations with extended choice periods, another fundamental question for the hyperbolic-decay model concerns exactly when a stimulus will serve as a conditioned reinforcer. In his textbook on learning, Domjan (1993) defined a conditioned reinforcer as a "stimulus that becomes an effective reinforcer because of its association with a primary, or unconditioned, reinforcer" (p. 394). This is a typical definition, and it is fine as a starting point, but it is vague about (1) exactly what constitutes an "association" with a primary reinforcer, and (2) what factors determine the strength of a conditioned reinforcer. The research reviewed in this paper has concentrated on the second issue. If the hyperbolic-decay model, as ex- 
pressed in Equation 5, is a suitable model of conditioned reinforcement, it offers a means of quantifying the strength (or value, or effectiveness) of a conditioned reinforcer. First, the model assumes (as Domjan's definition implies) that a stimulus must be at least occasionally paired with a primary reinforcer if it is to be classified as a conditioned reinforcer (so stimuli presented only during the ITI, or only on nonreinforced trials, do not become conditioned reinforcers, and should not be included in the calculation of $D_{i}$ ). Second, like a number of other theories, the model assumes that the strength of a conditioned reinforcer is inversely related to its duration (i.e., increasing $D_{i}$ causes $V$ to decrease). Third, the model states that the strength of a conditioned reinforcer is not a simple function of its average duration, because Equation 5 also takes into account any variability in $D_{i}$ across successive reinforcers. Thus, according to this model, a stimulus can become a strong conditioned reinforcer if it occasionally signals a short delay to the primary reinforcer, even though it may signal a much longer delay on other occasions. This feature of the hyperbolic-decay model is what enables it to make fairly successful predictions about preference for variability and about choices involving probabilistic reinforcers.

This method for calculating the strength of a conditioned reinforcer may seem fairly straightforward, but unfortunately there are complicating factors. Consider, for example, one part of Mazur's (1991) experiment, which included red-absent and red-present conditions (similar to those diagramed in Figure 9) plus a 60-sec red condition in which the red houselights were presented for a full $60 \mathrm{sec}$ on nonreinforced trials (and the usual $5 \mathrm{sec}$ on reinforced trials). Because the duration of the red houselights was lengthened in the $60-\mathrm{sec}$ red conditions, the hyperbolic-decay model predicts decreased preference for the probabilistic alternative (which should result in longer indifference points). Compared with the red-present conditions, indifference points from the $60-\mathrm{sec}$ red conditions did increase for 2 of the 4 subjects, but were essentially unchanged for the other 2 subjects. Thus only 2 of the 4 subjects showed the predicted effect.

Mazur (1991) speculated that these latter 2 pigeons might have learned to discriminate between the first $5 \mathrm{sec}$ of red houselights from the remaining $55 \mathrm{sec}$. For the first $5 \mathrm{sec}$ of the red houselights, there was no way to predict whether or not food would be delivered. However, if food was not presented after $5 \mathrm{sec}$ of red houselights, it was not presented at all. Therefore, for these 2 pigeons, the first $5 \mathrm{sec}$ of red houselights may have served as conditioned reinforcers (because they were sometimes paired with food), but not the remaining $55 \mathrm{sec}$ (because they were never paired with food).

If this speculation is correct, calculating the strength of a conditioned reinforcer with Equation 5 becomes problematic for cases in which it is possible for subjects to learn a temporal discrimination, because the same physical stimulus (e.g., red houselights) may serve as a stimulus for part of its duration but not for its entire duration. Furthermore, there may be large individual differ- ences if some subjects learn the temporal discrimination and others do not. This ambiguity about exactly when a stimulus will serve as a conditioned reinforcer may be an unwelcome complication, but it is probably unavoidable. The results from a few other experiments provide further examples of this problem. In Mazur's (1995) G10+, G30condition, the standard alternative delivered food after a 10 -sec delay with green houselights on half of the trials, but on the other half of the trials, the green houselights were presented for $30 \mathrm{sec}$ with no food (Table 1). Therefore, subjects might learn to discriminate between the first $10 \mathrm{sec}$ of green houselights (which were followed by food half of the time) and the remaining $20 \mathrm{sec}$ of green houselights (which were never followed by food). As already discussed, the mean indifference points for the 4 pigeons were close to those predicted by Equation 5, but there was greater between-subjects variability in this condition than in any other condition of the experiment. This was also the only condition in which it was possible for subjects to develop a temporal discrimination, so the large individual differences may again indicate that some subjects learned this discrimination and others did not.

In a study still in progress, I am continuing to study the effects of extending a putative conditioned reinforcer into time periods when there is no possibility of a food delivery. All 4 subjects in this experiment had extensive prior experience with the adjusting-delay procedure and with probabilistic reinforcement. In different conditions, the colored houselights were (1) extended well past the time when food might be delivered on nonreinforced trials, (2) presented both before and after the food on reinforced standard trials, or (3) presented both before and after food on both the standard and adjusting trials. With these experienced subjects, the ability to learn temporal discriminations appears to be the rule, because none of these large increases in the durations of the red and green houselights had any systematic effects on preference. In other words, the pigeons' preferences were controlled by the durations of the houselights during delays that might be followed by food, but were unaffected when the houselights were extended into time periods when food was never delivered.

Another case in which a single stimulus may have different conditioned reinforcing values in different circumstances is when the same stimulus is presented during the delays to food for two different choice alternatives. For example, Omino (1993) used a concurrent-chain schedule with a VI schedule as the initial link and two FT schedules as terminal links. The FT schedule was always longer for one of the two alternatives. In cued conditions, two different key colors were present during the two different FT schedules, but in uncued conditions both FT schedules were signaled by the same stimulus, blackout. The pigeons showed stronger preference for the shorter FT schedules in the cued conditions than in the uncued conditions, which is not surprising because it was easy to discriminate between the two FT schedules in the cued conditions. What may seem surprising at first glance, however, is that the birds did show some preference (albeit weaker) for the 
shorter FT schedules in the uncued conditions. Other studies comparing cued and uncued conditions have yielded similar results (Omino \& Ito, 1993; Williams \& Fantino, 1978). But if the same stimulus occurs in each terminal link, why do the animals show any preference at all?

One answer is that when the conditioned reinforcer is identical for the two alternatives, any remaining preference shows the effects of the delayed primary reinforcers (which are less delayed for one alternative than for the other). However, another explanation is that the subjects can learn to discriminate, for example, between blackout after a left peck and blackout after a right peck, so that what appears to be the same physical stimulus can have two different values in the two cases. The animal's position in the chamber or its behavior during the delays may also help it to discriminate between the two terminal links. There are sometimes fairly large differences between subjects in uncued conditions (see, e.g., Omino \& Ito, 1993), suggesting that some subjects learn the discrimination more readily than do others.

To complicate matters further, there can also be conditions in which a stimulus that is never paired directly with food may serve as a conditioned reinforcer, even if that stimulus is otherwise associated with the ITI. Mazur and Romano (1992) used a variation of the adjusting-delay procedure in which a peck on a green (standard) key led to a delay with green houselights, but food was presented only after every fourth green-houselight delay. Once the green key was chosen, however, the subject had to continue to choose this key until food was delivered (i.e., after every fourth green-key choice). Each of the four consecutive delay periods was called a "link," and in different conditions, the durations of the links varied. Furthermore, in some conditions, white houselights were presented in place of the green houselights after the first $4 \mathrm{sec}$ of each link. Figure 10 diagrams the sequence of events for the standard alternative in five different conditions of this ex- periment. Notice that in all of the conditions, food was presented in the fourth link, after a 4-sec delay with green houselights. Figure 10 shows that in the conditions labeled G4, G8, and G12, green houselights were present throughout the delays in each link, and the total delay time across the four links was 16,28, and $40 \mathrm{sec}$, respectively (not including the time the subjects needed to peck the green key at the start of each link). The right column in Figure 10 shows that, not surprisingly, the mean indifference points in these three conditions increased as delay time increased. (The adjusting key required only one peck on the red key per food delivery, not four, which might explain why the mean adjusting delays were longer than the total standard delays in two of these conditions.)

Of greater interest, however, were the results from the conditions labeled G4W4 and G4W8, in which the green houselights were presented for $4 \mathrm{sec}$ in each link, but the first three links also included additional delays with white houselights. The total time spent in the presence of the green houselights was the same as in Condition G4. However, the total delay to food, including the whitehouselight time, was the same as in Conditions G8 and G12, respectively. Would the indifference points in these conditions resemble those of the G4 condition, or would they approximate those of the G8 and G12 conditions? The right column of Figure 10 shows that the mean indifference points were in between-longer than in the G4 condition, but shorter than in the G8 and $\mathrm{G} 12$ conditions. The results for individual subjects varied considerably, however. For 2 subjects, the indifference points from the conditions with white houselights were not substantially different from those of the G4 condition. For the other 2 subjects, the indifference points from these conditions were substantially higher than in the G4 condition. In short, the time spent in the presence of the white houselights had little effect on preference for 2 subjects, but it did have an effect for the other 2 subjects.

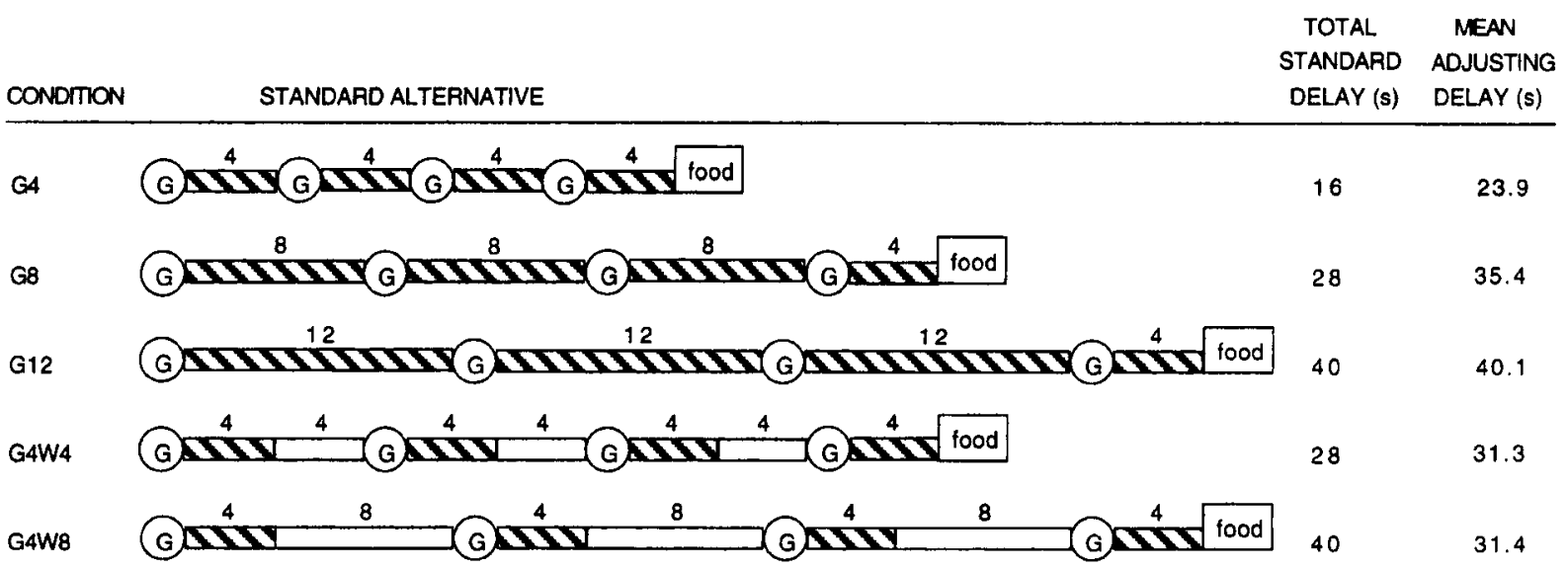

\section{DWV GREENHOUSEJGHTS}

WHITE HOUSELGHTS

Figure 10. The sequences of events that followed a choice of the green (standard) alternative in five different conditions of Mazur and Romano's (1992) experiment. 
Even for the latter subjects, however, the indifference points from the G4W4 and G4W8 conditions were shorter than those from the G8 and G12 conditions, respectively. This implies that each additional second of white houselights did not have as large an effect on preference as each additional second of green houselights. Nevertheless, these results show that for some subjects, time spent in the presence of a stimulus that is never directly paired with a primary reinforcer can also affect preference in this type of choice situation. These results might not seem particularly surprising (and indeed, the results from the 2 subjects that showed no effect of the white houselights might seem more surprising), but they do stand in distinct contrast to the results of Mazur (1989), where much larger variations in ITI durations had no systematic effects.

These findings suggest that making precise, quantitative predictions about the effects of delays and conditioned reinforcers may be an elusive goal in certain circumstances. When a potential conditioned reinforcer is extended into a time period when no primary reinforcer is ever delivered, some subjects may learn a temporal discrimination and others may not. When a stimulus not associated with the primary reinforcer is inserted into a series of conditioned reinforcers, this added stimulus may affect the preference of some subjects but not others. This ambiguity about what does and does not constitute a conditioned reinforcer makes it difficult to apply Equation 5 (or any other model of conditioned reinforcement). On the positive side, however, it should be emphasized that many of the choice situations described in this paper did not entail such ambiguity about what the conditioned reinforcer is. For the choices involving delay-amount tradeoffs or preference for variability, and for many of the choices involving probabilistic reinforcers, defining the conditioned reinforcer was comparatively straightforward, and for those choices the quantitative predictions of the hyperbolic-decay model were quite successful. These results give credence to the view that the hyperbolic-decay model provides an accurate method for quantifying the strength of a conditioned reinforcer. It remains to be seen whether an extension of this model, or any alternative model, can make successful predictions for the more ambiguous cases, especially those in which large individual differences among subjects are found.

\section{REFERENCES}

AiNSLIE, G. W. (1974). Impulse control in pigeons. Journal of the Experimental Analysis of Behavior, 21, 485-489.

AINSLIE, G. W. (1975). Specious reward: A behavioral theory of impulsiveness and impulse control. Psychological Bulletin, 82, 463-496.

BAUM, W. M. (1974). On two types of deviation from the matching law: Bias and undermatching. Journal of the Experimental Analysis of Behavior, 22, 231-242.

BAUM, W. M. (1979). Matching, undermatching, and overmatching in studies of choice. Journal of the Experimental Analysis of Behavior, 32, 269-281.

Baum, W. M., \& Rachlin, H. (1969). Choice as time allocation. Journal of the Experimental Analysis of Behavior, 12, 861-874.
BenZION, U., RAPAPORT, A., \& YAGIL, J. (1989). Discounting rates inferred from decisions: An experimental study. Management Science, $35,270-284$.

Cicerone, R. A. (1976). Preference for mixed versus constant delay of reinforcement. Journal of the Experimental Analysis of Behavior, 25, 257-261.

DAvison, M. C. (1969). Preference for mixed-interval versus fixed-interval schedules. Journal of the Experimental Analysis of Behavior, $12,247-252$.

Davison, M. C. (1972). Preference for mixed-interval versus fixed-interval schedules: Number of component intervals. Journal of the Experimental Analysis of Behavior, 17, 169-176.

Davison, M. C. (1983). Bias and sensitivity to reinforcement in a concurrent-chain schedule. Journal of the Experimental Analysis of Behavior, 40, 15-34.

DAviSON, M. C. (1988). Delay of reinforcers in a concurrent-chain schedule: An extension of the hyperbolic-decay model. Journal of the Experimental Analysis of Behavior, 50, 219-236.

Davison, M. C., \& TEMPLE, W. (1973). Preference for fixed-interval schedules: An alternative model. Journal of the Experimental Analysis of Behaviur, 20, 393-403.

Domjan, M. (1993). Domjan and Burkhard's 'The principles of learning and behavior' (3rd ed.). Pacific Grove, CA: Brooks/Cole.

DunN, R., \& SPETCH, M. L. (1990). Choice with uncertain outcomes: Conditioned reinforcement effects. Journal of the Experimental Analysis of Behavior, 53, 201-218.

DunN, R., Williams, B., \& Royalty, P. (1987). Devaluation of stimuli contingent on choice: Evidence for conditioned reinforcement. Journal of the Experimental Analysis of Behavior, 48, 117-131.

FanTINo, E. (1967). Preference for mixed- versus fixed-ratios. Journal of the Experimental Analysis of Behavior, 10, 35-43

FANTINO, E. (1969). Choice and rate of reinforcement. Journal of the Experimental Analysis of Behavior, 12, 723-730.

Fantino, E. (1977). Conditioned reinforcement: Choice and information. In W. K. Honig \& J. E. R. Staddon (Eds.), Handbook of operant behavior (pp. 313-339). Englewood Cliffs, NJ: Prentice-Hall.

Fantino, E., \& Davison, M. (1983). Choice: Some quantitative relations. Journal of the Experimental Analysis of Behavior, 40, 1-13.

FAntino, E., \& DUNN, R. (1983). The delay-reduction hypothesis: Extension to three-alternative choice. Journal of Experimental Psychology: Animal Behavior Processes, 9, 132-146.

Fantino, E., Preston, R. A., \& DunN, R. (1993). Delay reduction: Current status. Journal of the Experimental Analysis of Behavior, 60 , 159-169.

Field, D. P., Tonneau, F., Ahearn, W., \& Hineline, P. N. (1996). Preference between variable-ratio and fixed-ratio schedules: Local and extended relations. Journal of the Experimental Analysis of Behavior, 66, 283-295.

GiBBoN, J. (1977). Scalar expectancy theory and Weber's law in animal timing. Psychological Review, 84, 279-325.

GRACE, R. C. (1993). Violations of transitivity: Implications for a theory of contextual choice. Journal of the Experimental Analvsis of Behavior, 60, 185-201.

GRACE, R. C. (1994). A contextual model of concurrent-chains choice. Journal of the Experimental Analysis of Behavior, 61, 113-129.

GRACE, R. C. (1996). Choice between fixed and variable delays to reinforcement in the adjusting-delay procedure and concurrent chains Journal of Experimental Psychology: Animal Behavior Processes, 22, 362-383.

Green, L., Fisher, E. B., Perlow, S., \& Sherman, L. (1981). Preference reversal and self control: Choice as a function of reward amount and delay. Behaviour Analysis Letters, 1, 43-51.

Green, L., Fristoe, N., \& Myerson, J. ( 1994). Temporal discounting and preference reversals in choice between delayed outcomes. Psychonomic Bulletin \& Review, 1, 383-389.

Grossbard, C. L., \& MAZur, J. E. (1986). A comparison of delays and ratio requirements in self-control choice. Journal of the Experimental Analysis of Behavior, 45, 305-315.

HerRnSteIN, R. J. (1964). Aperiodicity as a factor in choice. Journal of the Experimental Analvsis of Behavior, 7, 179-182. 
Hull, C. L. (1943). Principles of behavior. New York: AppletonCentury-Crofts.

KILLEEN, P. (1968). On the measurement of reinforcement frequency in the study of preference. Journal of the Experimental Analysis of Behavior, 11, 263-270.

KILLEEN, P. R. (1982). Incentive theory: II. Models for choice. Journal of the Experimental Analysis of Behavior, 38, 217-232.

Killeen, P. R., \& Fantino, E. (1990). Unification of models for choice between delayed reinforcers. Journal of the Experimental Analysis of Behavior, 53, 189-200.

MACEWEN, D. (1972). The effects of terminal-link fixed-interval and variable-interval schedules on responding under concurrent-chained schedules. Journal of the Experimental Analysis of Behavior, 18, 253-261.

MazUR, J. E. (1984). Tests of an equivalence rule for fixed and variable reinforcer delays. Journal of Experimental Psychology: Animal Behavior Processes, 10, 426-436.

MAZUR, J. E. (1986a). Choice between single and multiple delayed reinforcers. Journal of the Experimental Analysis of Behavior, 46, 67-77.

MAZUr, J. E. (1986b). Fixed and variable ratios and delays: Further tests of an equivalence rule. Journal of Experimental Psychology. Animal Behavior Processes, 12, 116-124.

MAZUR, J. E. (1987). An adjusting procedure for studying delayed reinforcement. In M. L. Commons, J. E. Mazur, J. A. Nevin, \& H. Rachlin (Eds.), Quantitative analyses of behavior: Vol. 5. The effect of delay and of intervening events on reinforcement value (pp. 55-73). Hillsdale, NJ: Erlbaum.

MazUR, J. E. (1989). Theories of probabilistic reinforcement. Journal of the Experimental Analvsis of Behavior, 51, 87-99.

MAZUR, J. E. (1991). Choice with probabilistic reinforcement: Effects of delay and conditioned reinforcers. Journal of the Experimental Analysis of Behavior, 55, 63-77.

MAZUR, J, E. (1995). Conditioned reinforcement and choice with delayed and uncertain primary reinforcers. Journal of the Experimental Analysis of Behavior, 63, 139-150.

MazUR, J. E., \& Romano, A. (1992). Choice with delayed and probabilistic reinforcers: Effects of variability, time between trials, and conditioned reinforcers. Journal of the Experimental Analysis of Behavior, 58, 513-525.

MCDIARMid, C. G., \& Rilling, M. E. (1965). Reinforcement delay and reinforcement rate as determinants of schedule preference. Psychonomic Science, 2, 195-196.

Millar, A., \& Navarick, D. J. (1984). Self-control and choice in humans: Effects of video game playing as a positive reinforcer. Learning \& Motivation, 15, 203-218.

Myerson, J., \& Green, L. (1995). Discounting of delayed rewards: Models of individual choice. Journal of the Experimental Analysis of Behavior, 64, 263-276.

Navarick, D. J. (1985). Choice in humans: Functional properties of reinforcers established by instruction. Behavioural Processes, 11, 269-277.

NAVARICK, D. J. (1986). Human impulsivity and choice: A challenge to traditional operant methodology. Psychological Record, 36, 343-356.

NAVARICK. D. J., \& FAntinO, E. (1972). Transitivity as a property of choice. Journal of the Experimental Analysis of Behavior, 18, 389-401.

OMINO, T. (1993). A quantitative analysis of sensitivity to the conditioned reinforcing value of terminal-link stimuli in a concurrent-chains schedule. Journal of the Experimental Analssis of Behavior, 60, 587-594.
OMINo, T., \& ITO, M. (1993). Choice and delay of reinforcement: Effects of terminal-link stimulus and response conditions. Journal of the Experimental Analysis of Behavior, 59, 361-371.

Rachlin, H., \& GreEN, L. (1972). Commitment, choice, and self-control. Journal of the Experimental Analysis of Behavior, 17, $15-22$.

Rachlin, H., Logue, A. W., Gibbon, J., \& Frankel, M. (1986). Cognition and behavior in studies of choice. Psychological Review, 93, 33-45.

RaINeRI, A., \& RaChLin, H. (1993). The effect of temporal constraints on the value of money and other commodities. Journal of Behavioral Decision Making, 6, 77-94.

RIDER, D. P. (1983). Preference for mixed versus constant delays of reinforcement: Effect of probability of the short, mixed delay. Journal of the Experimental Analysis of Behavior, 39, 257-266.

Rodriguez, M. L., \& LoGUE, A. W. (1988). Adjusting delay to reinforcement: Comparing choice in pigeons and humans. Journal of Experimental Psychology: Animal Behavior Processes, 14, 105-117.

Sherman, J. A., \& Thomas, J. R. (1968). Some factors controlling preference between fixed-ratio and variable-ratio schedules of reinforcement. Journal of the Experimental Analysis of Behavior, 11, 689-702.

Shul L, R. L., \& Spear, D. J. (1987). Detention time after reinforcement: Effects due to delay of reinforcement? In M. L. Commons, J. E. Mazur, J. A. Nevin, \& H. Rachlin (Eds.), Quantitative analyses of behavior: Vol. 5. The effect of delay and of intervening events on reinforcement value (pp. 187-204). Hillsdale, NJ: Erlbaum.

Solnick, J. V., Kannenberg, C. H., Eckerman, D. A., \& Waller, M. B. (1980). An experimental analysis of impulsivity and impulse control in humans. Learning \& Motivation, 11, 61-77.

Spetch, M. L., Belke, T. W., Barnet, R. C., Dunn, R., \& Pierce, W. D. (1990). Suboptimal choice in a percentage-reinforcement procedure: Effects of signal condition and terminal-link length. Journal of the Experimental Analysis of Behavior, 53, 219-234.

SPETCh, M. L., Mondloch, M. V., BelKe, T. W., \& DunN, R. (1994). Determinants of pigeons' choice between certain and probabilistic outcomes. Animal Learning \& Behavior, 22, 239-251.

SQuires, N., \& FANTINo, E. (1971). A model for choice in simple concurrent and concurrent-chains schedules. Journal of the Experimental Analysis of Behavior, 15, 27-38.

Williams, B. A., \& DUNN, R. (1991). Preference for conditioned reinforcement. Journal of the Experimental Analysis of Behavior, 55, 37-46.

WILliams, B. A., \& FANTINO, E. (1978). Effects on choice of reinforcement delay and conditioned reinforcement. Journal of the Experimental Analysis of Behavior, 29, 77-86.

\section{NOTES}

1. Grace (1994) actually presented a slightly different but equivalent form of this equation that used mean durations rather than the reinforcement rates $\left(r_{1 \mathrm{~L}}, r_{1 \mathrm{R}}, r_{2 \mathrm{~L}}\right.$, and $\left.r_{2 \mathrm{R}}\right)$ used in Equation 8. The two equations are equivalent because mean reinforcement rates are simply the reciprocals of mean durations. Reinforcement rates were used in Equation 8 because this form of the equation is more similar to the generalized matching law, and because it makes it easier to explain how the hyperbolic-decay equation can be incorporated into the model.

(Manuscript received December 5, 1996; revision accepted for publication January $28,1997$. ) 